\title{
Author Index Vol. 19, No. 3, 1997
}

Neumscience

Baader, S.L. $283 \quad$ Mize, R.R. 260

Black, S.M. 224 Murphy, S. 223

Bredt,D.S. 223,224 Salvatore, M.F. 260

Brenman,J.E. 224 Scheiner, C.A. 260

Bucher, S. 283Schilling, K. 283

Chao, D.S. $224 \quad$ Smith, S.S. 274

Chen, S. 274 Spasic, Z. 255

|ip,R.J. 260 Vizzard, M.A. 232

Gu,Y. 255 Wu,W. 255

Li, J. $274 \quad$ Xia,H. 224

Lin,R.C.S. $274 \quad$ Yu,W.-h.A. 247

KAR.G.GEK (C) 1997 S.Karger AG

Basel 291 